\title{
EDUCAÇÃO SUPERIOR NO BRASIL. DEMOCRATIZAÇÃO OU MASSIFICAÇÃO MERCANTIL?
}

\author{
Valdemar Sguissardi
}

\begin{abstract}
RESUMO: Este texto visa explicitar como, no âmbito de uma economia ultraliberal com predominância financeira e de um Estado semiprivado, que lhe é funcional, está sendo anulada a fronteira entre o público e o privado/mercantil, e promovida uma expansão da educaçáo superior que se mantém, de um lado, como de elite e de alta qualificaçáo para poucos, e, de outro, como de massas e de baixa qualificaçáo para muitos pondo em xeque sua pretendida democratização. A interpretação dos dados referentes ao estatuto jurídico das instituiçóes e respectivas matrículas, à concentraçáo por área de saber, à presença de fundos de investimento nacionais e transnacionais associados às grandes empresas do setor educacional etc., autoriza a hipótese de que a educaçáo superior, no Brasil, vive um intenso processo de transformaçáo de um direito em mercadoria.
\end{abstract}

Palavras-chave: Educação Superior. Democratização da Educação Superior. Massificação da Educação Superior. Política de expansão da Educaçáo Superior.

\section{HighER EDUCATION IN BRAZIL. DEMOCRATIZATION OR PROFIT ORIENTED MASSIFICATION?}

\begin{abstract}
This article aims to explain how - within an ultra-liberal economy with financial dominance and a semi-private State, that is functionally useful to this economy - the frontier between the public and the private/mercantile spheres is being annulled. It also aims to show how an expansion of higher education is being promoted that remains elitist and highly qualified for a few, on the one side, and as a mass product and of low quality for many, on the other. This calls into question its intended democratization. The interpretation of the data concerning the legal status of the institutions and their respective enrollments, the concentration by area of knowledge, the presence of national and transnational investment funds associated to large companies in the education sector, etc., allow the hypothesis that higher
\end{abstract}

\footnotetext{
* Universidade Federal de São Carlos (UFSCar), São Carlos, SP., Brasil. E-mail de contato: vsguissardi@gmail.com.
} 
education, in Brazil, lives an intense process of transformation of a right into a merchandise.

Keywords: Higher education. Higher education democratization. Higher education massification. Higher education expansion policy.

\section{L'ENSEIGNEMENT SUPÉRIEUR AU BRÉSIL. DÉMOCRATISATION OU MASSIFICATION MARCHANDE?}

RÉSUMÉ: Cet article vise à expliquer comment, dans une économie ultra-libérale à l'égard financier et dans un État semi-privé, la frontière entre le public et le privé/marchand est en train d'être annulée et comment on favorise une expansion de l'enseignement supérieur qui reste, d'un côté, élitiste et fortement qualifié pour quelques-uns et, de l'autre, massifié et de faible qualité pour d'autres mettant en cause sa prétendue démocratisation. L'interprétation des données concernant le statut juridique des institutions et de leurs effectifs, la concentration par domaine de la connaissance, la présence de fonds d'investissement nationaux et transnationaux associés à de grandes entreprises du secteur de l'éducation, etc., autorise l'hypothèse que l'enseignement supérieur, au Brésil, vit un intense processus de transformation d'un droit acquis en simple marchandise.

Mots-clés: Enseignement supérieur. La démocratisation de l'enseignement supérieur. La massification de l'enseignement supérieur. Politique d'expansion de l'éducation supérieur.

\section{Introdução ${ }^{1}$}

Não é, portanto, verdadeira a tese amplamente difundida e por vezes defendida mesmo por acadêmicos e pesquisadores de que o campus reflete a sociedade. Os dados mostram que, ao contrário, o campus é um espelho que distorce a imagem da sociedade ou, dito de outra forma, o campus, como um agente social ativo, aguça as distorçóes existentes na sociedade. (RISTOFF, 2014, p. 731)

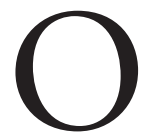

estudo diagnóstico da "Política de expansão da (e acesso à) educação superior no Brasil, de 2002 a 2012" (SGUISSARDI, 2014), realizado em consultoria, em meados de 2014, para uma Comissão do Conselho Nacional de Educação (CNE) que se ocupa dessa temática, com especial atenção ao processo de sua mercantilização, aponta para uma clara, e a cada dia 
mais evidente, contradição quando se analisam e interpretam os dados dessa realidade: estamos diante de um movimento de democratização ou de massificação mercantil?

Com esta exposição, visa-se explicitar como, no âmbito de uma economia ultraliberal, com predominância financeira ${ }^{2}$, e de um Estado semiprivado, que lhe é funcional, estão sendo anuladas as fronteiras entre o público e o privado/ mercantil ao promover-se uma expansão da educação superior (ES) que a mantém como de elite e de alta qualificação para poucos, enquanto adquire traços de "sistema" de massas e de baixa qualificação para muitos. Isto poria em dúvida o alcance das pretendidas metas oficiais de sua democratização. A análise e interpretação dos dados referentes ao estatuto jurídico das instituiçóes e respectivas matrículas, à frequência ao turno noturno e à $\mathrm{EaD}$, à concentração dos cursos e matrículas por área de conhecimento, à presença de fundos de investimento (de private equity ${ }^{3}$ ) nacionais e transnacionais que se associam às grandes empresas do setor educacional etc., autorizam a hipótese de que a educação superior, no Brasil, vive um intenso processo de transformação de um direito ou "serviço público" em "serviço comercial" ou mercadoria, isto é, um processo de massificação mercantilizadora que anula as fronteiras entre o público e o privado-mercantil e impede uma efetiva democratização do "subsistema". Ao menos no nível da graduação.

Constata-se que o Estado, tendo ideológica e operacionalmente dificuldade de apostar no investimento maciço na educação superior, tem buscado, via políticas focais de curto alcance - Programa Universidade para Todos (Prouni) e Fundo de Financiamento Estudantil (Fies), em especial -, garantias de alguma igualdade de condiçóes de acesso, mas que não preveem igualdade de condições de permanência e, em especial, de sucesso no mercado de trabalho.

Verifica-se, no âmbito desse estudo diagnóstico, a ausência de um planejamento estratégico ou de um simples plano nacional de graduação a partir de adequado diagnóstico da realidade; plano que pudesse prever a expansão, com participação majoritária de matrículas no setor público e moderado crescimento no setor privado. $\mathrm{Ou}$, ao menos, que, por priorizar regióes e sub-regióes, tipo de instituição, cursos em determinadas áreas do conhecimento, garantisse, por um lado, os 40\% de matrículas em instituiçóes de educação superior (IES) públicas, previstos como meta do Plano Nacional de Educação (PNE) 2014-2024, e, por outro, freasse a expansão da educação superior em IES privado-mercantis de baixa qualidade.

Observa-se que o que sobressai ao longo das últimas décadas é o esforço - mediante as supracitadas políticas focais e uma legislação permissiva quanto à natureza comercial das organizaçóes e instituiçóes educacionais - visando à expansão quantitativa, não importando muito ou quase nada se essa expansão se dá 
como usufruto de um direito público ou se apenas como compra de um serviço, produto comercial ou mercadoria.

O proposto na agenda dos Acordos Gerais de Comércio e Serviços (AGCS) da Organização Mundial do Comércio (OMC), isto é, a transformação da educação superior em serviço comercial, prevalece e, embora oficial e formalmente não reconhecido, é posto em prática com sua marca em mais de $4 / 5$ das instituiçôes que contam com $2 / 3$ de todas as matrículas da educação superior de graduação no país.

Esse estudo diagnóstico revela o "pioneirismo" e a "dianteira" do país na constituição de empresas educacionais que abrem seu capital e fazem oferta pública inicial $\left(\mathrm{IPO}^{4}\right)$, isto é, lançam açóes no mercado de açóes com apoio de fundos nacionais e transnacionais de private equity, que têm, em geral, comandado o processo de preparo dessas empresas para sua abertura de capital e IPO na bolsa de valores (Bovespa). Ao longo dos últimos dois ou três anos e até o final de 2014 ou até a edição das Portarias 21 e 23 do Fies, de 29/12/2014, o setor educacional do mercado de açóes foi o mais lucrativo dentre os 15 ou 16 setores da economia presentes na Bovespa. De agosto de 2012 a agosto de 2014, por exemplo, enquanto o Ibovespa (índice do total de cerca de 350 empresas) teve uma redução de 3,67\%; a Vale (VALE5), redução de 13,48\%; e a Petrobras (PETR4), valorização de 9,32\% de suas açóes; a Kroton (KROT3) teve uma valorização de 314\% e a Estácio (ESTC3), 240,97\% de suas respectivas açóes.

Esta situação, de abertura do mercado para as IES privadas em 1997 (Decretos 2.207 e 2.306) e o IPO das quatro primeiras empresas educacionais a fazê-lo (Kroton, Estácio, Anhanguera e SEB - Sistema Educacional Brasileiro ou Colégio Osvaldo Cruz, Dom Bosco e Pueri Domus), em 2007, constituiu-se muito provavelmente no principal fator de sua acelerada expansão e, ao mesmo tempo, de desaparição, nos últimos 10 a 15 anos, de 2/3 das IES comunitárias ou confessionais e respectivas matrículas.

Quanto ao acesso à educação superior, o fator determinante que mantém o Brasil no terço de menor cobertura ou taxa líquida dentre os países da América Latina, apesar de ser a $7^{\text {a }}$ economia (PIB) do planeta, é a imensa desigualdade social que aqui se verifica. É ela, certamente, como amplamente demonstrado, o principal fator de produção da expansão elitista da educação superior, tanto na graduação como na pós-graduação. E aqui vale chamar a atenção para o duplo sentido do elitismo: a) como pertencimento a uma população, que não chega a $1 / 5$ do total da faixa etária adequada, que tem acesso à educação superior; e como qualidade superior de formação, que somente é possível em raros casos na graduação e na pós-graduação, esta acessível a menos de 5\% dos concluintes da graduação. 
Sobre o direito à educação superior, como direito fundamental, mas não subjetivo como o é o ensino fundamental, verifica-se que constitucionalmente ele é um direito de prestação mais frágil e que supóe uma necessária e longa luta para garanti-lo como direito universal.

Antes de questionar-se a constitucionalidade do oferecimento da educação superior como serviço comercial por empresas de capital aberto, transnacionais na prática, e açóes na Bolsa de Valores, é necessário saber que a existência de instituiçóes de educação com fins de lucro tem respaldo na CF 88 e na LDB/96, ali reconhecida ainda que a contrário sensu, e, principalmente nos Decretos 2.207 e 2.360 de 1997, regulamentadores da LDB/96, como se verá em detalhes adiante.

Para explicitar como estão sendo gradativa e celeremente anuladas as fronteiras entre o público e o privado/mercantil na ES de graduação e demonstrar a hipótese de que este nível de educação, no Brasil, vive um intenso processo de transformação de um direito ou "serviço público" em "serviço comercial” ou mercadoria, isto é, que esse não seria um processo de democratização mas de massificação mercantil, necessita-se aprofundar alguns conceitos e categorias de análise ao mesmo tempo em que se exponham alguns dados dos censos estatísticos oficiais que sustentem a pertinência dessa hipótese.

\section{I - Economia ultraliberal, predominância financeira e Estado semiprivado em que os interesses privado-mercantis se sobrepõem aos interesses públicos}

O dilema "democratização ou massificação mercantil" da educação superior em seu processo de expansão em curso não se explica por si mesmo. Dá-se no contexto do ajuste neoliberal e da assim chamada mundialização do capital, que tem na predominância financeira sua marca mais saliente e operacional. De fato, se examinado o processo de expansão da ES desde o ano de 1997, quando se abriram as cancelas para a efetiva constituição de IES com fins lucrativos e, principalmente, a partir de 2007, quando da abertura de capital e IPO na Bolsa de Valores paulista das primeiras quatro companhias do campo educacional, verificar-se-á que, como escreveu Ryon Braga, da Hoper Consultoria, praticamente todas essas grandes empresas tiveram e têm a participação acionária de fundos de investimento, em geral transnacionais:

Dos cinco maiores grupos educacionais brasileiros, que juntos possuem 800 mil alunos, quatro deles são comandados por empresas do setor financeiro. Entre as 15 maiores empresas educacionais do país nove possuem um fundo ou banco de 
investimentos na sua estrutura de gestão e governança, ou $60 \%$ do total.

Entre os cinco maiores grupos - Estácio, Unip, Anhanguera, Kroton e Laureate - somente a Unip não tem a presença do setor financeiro na sua administração. A Estácio é administrada pelo fundo GP[ $\left.{ }^{5}\right]$; a Anhanguera pelo banco Pátria [6]; a Kroton pela Advent International $\left[^{7}\right]$, e a Laureate pelo fundo americano $\operatorname{KKR}\left[^{8}\right]$.

Além destes, vários outros fundos de investimentos estão presentes na educação brasileira, tais como Cartesian Group [ $\left.{ }^{9}\right]$ na Faculdade Maurício de Nassau, o Capital Group $\left[{ }^{10}\right]$ no Grupo Ibmec, o Fama $\left[{ }^{11}\right]$ na SEB (COC), o banco americano Best Associates (Texas) $\left[{ }^{12}\right]$ no Centro Universitário Jorge Amado, entre outros. (BRAGA, 2014, apud SGUISSARDI, 2014, p. 162)

A entrada do setor financeiro na educação superior do Brasil ocorre, portanto, com a associação da Kroton (então Pitágoras), em 2001, com o Grupo Apollo International, seguida pela compra da Universidade Anhembi-Morumbi pela Laureate, em 2006, e, especialmente, pela abertura de capital das empresas Anhanguera, Kroton, Estácio e SEB em 2007.

A abertura do capital dessas empresas ao mercado de açôes e a valorização destas últimas possibilitam o aumento de seu capital, a compra de outras instituiçóes menores, espalhadas no país, e, com isso, a formação de grandes grupos empresariais, também denominados "redes" [...]. (VALE; CHAVES; CARVALHO, 2013, p. 8, apud SGUISSARDI, 2014, p. 163)

A mundialização do capital, na esteira da crise do Estado do Bem-Estar Social, e o ajuste neoliberal que se disseminou pela Europa, EUA e Japão, mas também pela América Latina, do Chile e do México, entre outros, ainda em meados da década de 1970, chega ao Brasil a partir do final dos anos 1980 e início dos 1990, quando do Consenso de Washington (1989), e no Governo de Collor de Mello (1990-91) [N.E.: Presidente Fernando Affonso Collor de Mello]. No Brasil, esse movimento adquire especial força a partir de 1995, quando da Reforma do Estado sob o comando do Presidente Fernando Henrique Cardoso e do Ministro da Administração e Reforma do Estado (Mare), José Carlos Bresser-Pereira. Reforma que apontava para a criação de organizaçóes sociais em lugar das autarquias e fundações públicas mantenedoras das Instituições Federais de Ensino Superior (Ifes). Estas organizaçóes sociais liberariam o Estado da obrigatória e constitucional manutenção das Ifes. Estas deveriam buscar junto a órgãos públicos ou privados os recursos financeiros que não lhes fossem garantidos pelo Fundo Público. 


\section{I.1. - Ajuste neoliberal, privatização e mercantilização}

Os primeiros passos do ajuste neoliberal, que primava pelo esvaziamento do polo social-público do Estado e fortalecimento de seu polo privado-mercantil, seriam concomitantes com os da liberaçấo do campo da educaçáo superior para o mercado a partir de 1997. No caso da economia, este movimento de ajuste neoliberal inicia-se com a desregulação e flexibilização das relações de trabalho, e pela redução e privatizaçáo dos sistemas de seguridade social. A retirada do controle estatal sobre empresas e serviços foi o passo seguinte, pelo qual o grande capital recebeu do Estado, para exploração privada e lucrativa, complexos industriais inteiros e serviços de importância básica para o país, como distribuição de energia, transportes, telecomunicação, saneamento básico, saúde e educação. (NETTO; BRAZ, 2007)

Ao mesmo tempo e sob pressão de organismos multilaterais, como o Banco Mundial e o Banco Interamericano do Desenvolvimento (BID), o então Ministro da Educação, Paulo Renato de Souza, ex-vice-diretor do BID em Washington, conduz o quase desmonte do "setor" federal da educação superior, congelando os recursos financeiros e salários, e não criando nenhuma Ifes ao longo de dois mandatos presidenciais (1995-2002). Nesse mesmo tempo patrocinava o arcabouço jurídico - Decretos 2.207 e 2.306 de 1997 - para a legalização do "negócio" da educação superior. Nisto seguia à risca as recomendaçôes do Banco Mundial que, mediante três documentos - Financing education in developing countries - An exploration of policy options (WORLD BANK, 1986), de 1986; Higher education: the lessons of experience (WORLD BANK, 1994), de 1994; e The financing and management of higher education - A status report on worldwide reforms, (WORLD BANK, 1998) - disseminava algumas "teses" que respaldariam as açôes de governos dispostos a dar consequência ao ajuste neoliberal no campo educacional.

O primeiro desses três documentos iria defender a "tese" do maior retorno privado e social dos investimentos em educaçáo básica que o dos investimentos em educação superior. Essa tese iria sofrer revisão, ou mesmo rejeição, 14 anos após no documento Higher education in developing countries: peril and promise (WORLD BANK, 2000), fruto de uma parceria entre o Banco Mundial e a Unesco.

O segundo, além de fazer um extenso diagnóstico da crise universitária, aponta o déficit público crônico de alguns Estados Nacionais como sendo consequência, também, do suposto excessivo suporte do fundo público à educação superior e em especial às universidades de "modelo europeu" (universidades neo-humboldtianas de pesquisa), e defende a chamada universidade de ensino, da qual desaparece em especial sua atividade-fim, a pesquisa. Essa "tese" irá conduzir a 
outras recomendaçóes: a maior diferenciação institucional, pela via do privado, e busca, pelas IES públicas, de diversificação de fontes de financiamento, incluindo entre essas a participação dos estudantes, audiência aos sinais do mercado, além de sugerir uma estreita vinculação entre os montantes de financiamento e os resultados. (WORLD BANK, 1994, p. 4 e 29)

O terceiro, além de constatar o resultado das recomendaçóes dos documentos anteriores - expansão de matrículas e de IES, cada vez mais diferenciadas; redução do custo/aluno; orientações e soluçóes do mercado; diversificação de fontes ou busca de recursos não-estatais - observa que essas reformas, em 1998, estariam muito mais "[...] orientadas para o mercado do que para a propriedade pública ou para a planificação e regulação estatais [...]” e que isto se deveria à “[...] crescente importância que em quase todo o mundo têm adquirido o capitalismo de mercado e os princípios da economia neoliberal [...]”. Com esse preâmbulo, o Banco adianta sua nova tese: o ensino superior seria um bem antes privado que público, porque ele responderia a muitas das condiçóes ou características de um bem privado "que se pode subordinar às forças do mercado". (WORLD BANK, 1998, p. 4)

É nesse contexto que se estanca, no Brasil, a expansão da educação superior pública federal, reduzem-se os recursos a ela destinados de 0,91\% para 0,54\% do PIB de 1995 a 2003; institui-se o Prováo na graduação e o modelo Capes de avaliação na pós-graduação, em 1996/97/98, e, principalmente, editam-se os dois Decretos - 2.207/97 e 2.306/97 - que irão legalizar o negócio mercantil na educação. Assim reza o artigo $7^{\circ}$ deste último:

As instituiçóes privadas de ensino, classificadas como particulares em sentido estrito, com finalidade lucrativa, ainda que de natureza civil, quando mantidas e administradas por pessoa física, ficam submetidas ao regime da legislação mercantil, quanto aos encargos fiscais, parafiscais e trabalhistas, como se comerciais fossem equiparados seus mantenedores e administradores ao comerciante em nome individual. ${ }^{13}$

A edição desses decretos, em 1997, vai desencadear um movimento sem precedentes de mudança estatutária e de regime administrativo do conjunto das IES privadas de 1997 a 1999: neste ano, segundo dados do Censo da Educação Superior do Inep, as IES particulares, com fins de lucro, já eram 58\% do total de 905 IES privadas ou 48\% do total de 1.097 públicas e privadas. Passados mais 11 anos, em 2010, as IES privadas particulares ou privado-mercantis já eram 77,8\% e, hoje, possivelmente ultrapassem $80 \%$ das cerca de 2.400 IES do país.

Como se observa, a mercantilização da educação superior no país, após esse passo jurídico, não irá mais deter-se. Sua marcha irá ultrapassar incólume os 
diversos mandatos presidenciais que se sucedem a partir de 1997. Mas será em 2007, com a abertura de capital e IPO na Bovespa das quatro primeiras empresas educacionais que se dará um passo decisivo em relaçáo tanto à mercantilizaçáo da educação superior quanto à oligopolização do setor.

\section{I.2 - Oligopolização do mercado educacional}

Como se verifica na Tabela 1 , uma única empresa - Kroton que hoje incorpora a Anhanguera - já detém cerca de $20 \%$ do total de matrículas do setor privado e, se consideradas as 11 maiores empresas de um total de cerca de 2 mil IES, que compóem o total das IES privadas, este percentual ascende a $40 \%$ do total dessas IES privadas, total que correspondia em 2012 a 73\% das matrículas públicas e privadas do país.

\section{Tabela 1}

Os 12 maiores grupos educacionais com fins lucrativos no Brasil - 2013

\begin{tabular}{|c|c|c|c|c|}
\hline Ordem & Grupo/Instituição & $\begin{array}{l}\text { Recei ta líqui da em } \\
\text { RS milhões }\end{array}$ & Número de alunos & $\%$ Mercado \\
\hline 10. & Kroton & 2.015 & 519.000 & 9,5 \\
\hline 20. & Anhanguera & 1.812 & 442.000 & 8,1 \\
\hline 30. & Estácio & 1.731 & 315.700 & 5,8 \\
\hline 40. & Unip & 1.431 & 247.520 & 4,5 \\
\hline 50. & Laureate & 1.115 & 170.000 & 3,1 \\
\hline 60. & Uninove & 584 & 134.000 & 2,5 \\
\hline 70. & Unicsul & 529 & 55.000 & 1 \\
\hline 80. & Anima & 461 & 49.000 & 0,9 \\
\hline 90. & Ser Educacional & 457 & 98,8 & 1,8 \\
\hline 100 & Whitney & 343 & 40.000 & 0,7 \\
\hline 110. & Devry & 242 & 30.000 & 0,6 \\
\hline 120. & Tiradentes & 236 & 40,7 & 0,7 \\
\hline & Subtotal & 10.956 & 2.141 .720 & 39,3 \\
\hline \multicolumn{2}{|c|}{ Total do Setor Privado } & 32.040 & 5.448 .730 & 100 \\
\hline
\end{tabular}

Fontes: Tabela elaborada com dados de Hoper (apud MAIA, 2014, p. 39).

Esse processo de transformação de um direito ou serviço público em serviço comercial ou mercadoria, como já sinalizado, dá-se no interior de um Estado reformado para conformar-se ao ajuste ultraliberal da economia; de um Estado que não é sinônimo de interesses públicos, mas que tende a representar de modo prioritário os interesses privado-mercantis. As afirmaçóes de Octávio Ianni (2004), ao analisar as relaçóes do Estado com o capital no Século XX, podem ser aplicadas para se compreender esse fenômeno da mercantilização da educação 
superior e da suposta desaparição das fronteiras entre o público e o privado-mercantil. Para Ianni, o Estado tende a secundarizar as condiçóes institucionais e os "processos sociais, políticos e culturais [educacionais]" em benefício dos processos que visam a acumulação do capital e que determinam e orientam o essencial das atividades estatais. Entre as principais funções do Estado na relação com o capital destacar-se-ia a "dinamização das virtualidades do sistema de mercado". (IANNI, 2004, p. 18)

Não seria extrapolar os limites da interpretação decorrente dessas afirmaçóes de Ianni se se disser que a edição dos dois decretos acima mencionados, a autorização do Cade/Ministério da Fazenda e da Comissão de Valores Mobiliários (CVM) para abertura de capital e ingresso no mercado de açôes de empresas educacionais e o implemento de programas como o Prouni e o Fies são formas de o Estado dinamizar as virtualidades do sistema de mercado em detrimento da concepção da educação superior como um direito ou serviço público.

\section{II - Políticas sociais e programas de democratização do acesso à educação superior - desigualdade social e políticas focais (Prouni e Fies)}

É no âmbito desse Estado, que privilegia a “[...] dinamização das virtualidades do sistema de mercado [...]” e os processos que visam a acumulação do capital, que se inserem as políticas sociais públicas, como a da expansão da educação superior e de sua pretendida democratização.

Apesar de políticas sociais do Estado, não se pode entendê-las como sendo independentes da predominância do polo privado-mercantil sobre o polo social e público do Estado. Não são autônomas. Desenvolvem-se

[...] pressionadas no âmbito dessa correlação de forças representada pelos interesses econômico-políticos dominantes e os das classes sociais dominadas, especialmente em país que se destaca pelo altíssimo grau de desigualdade social. (SGUISSARDI, 2014, p. 21)

Segundo Belloni, Magalhães e Sousa (2000, p. 33) existiriam pelo menos três tipos de políticas sociais: congruentes, complementares e reparadoras ou compensatórias. As primeiras seriam as que se atrelam à política econômica básica de um governo; as segundas são as destinadas a fornecer "elementos reforçadores" dos "objetivos e metas principais" dessa política econômica central; e as terceiras, reparadoras ou compensatórias, são as que devem “[...] atuar sobre os danos 
ou consequências nefastas das políticas [econômicas] básicas com o objetivo de atenuá-los [...]".

Estas últimas têm sido igualmente denominadas de políticas focais por oposição às políticas de caráter universal. As políticas sociais são denominadas de universais quando atuam sobre aspectos estruturais do sistema econômico-político, como aumento real e constante do salário mínimo, ou para eliminar as causas do desemprego e da exclusão social. As políticas focais destinam-se a parcelas da população trabalhadora ou excluída e têm alcance limitado, pois não atuam sobre as causas da desigualdade social produtora da exclusão.

\section{II.1 - Acesso à educação superior}

Para responder à questão do dilema democratização ou massificação mercantil é necessário examinar como se têm dado o acesso à educação superior, a permanência até o final dos estudos e o sucesso ou insucesso dos titulados no mercado de trabalho.

$\mathrm{O}$ acesso à educação superior dos jovens de metade da população brasileira, cujas famílias têm renda de até três salários mínimos (SM), não depende basicamente da vontade dos jovens em idade adequada ou de suas respectivas famílias, mas do nível socioeconômico destas. É num país em que o rendimento médio do $1 \%$ mais rico é cerca de 40 vezes maior que o dos $40 \%$ mais pobres (FREIRE, 2014); em que cerca de 50\% das famílias têm renda familiar de até três SM e apenas $7 \%$ possuem renda superior a 10 SM; e em que menos de $27 \%$ das matrículas da educação superior estão em IES públicas gratuitas, que a exigência constitucional de "[...] igualdade de condiçôes para o acesso e permanência na escola [...]" (CF 88, art. 206, inciso I) adquire o significado de uma verdadeira utopia. É necessário enfatizar que essa utópica igualdade de condiçóes para o acesso à, e de permanência na, educação superior é, como nos demais níveis, condição básica da democratização desse nível de educação. Isto é, não se pode falar em processo de democratização sem que se verifique algum grau importante de igualdade de condições para todos os candidatos a uma vaga na educação superior.

Em dois estudos recentes de Dilvo Ristoff - Perfil socioeconômico do estudante de graduação: uma análise de dois ciclos completos do Enade (2013); e $O$ novo perfil do campus brasileiro: uma análise do perfil socioeconômico do estudante de graduação (2014) - verificam-se significativas mudanças no perfil socioeconômico dos estudantes de graduação, em grande medida provocadas pelo novo perfil da população de baixa renda, com programas como Bolsa Família e aumento real do SM, e, sem dúvida, por programas como o Prouni e, especialmente, o Fies. Essas mudanças estão relacionadas, nesses estudos, a quatro variáveis ou dimensóes, tais 
como a renda mensal das famílias, sua origem escolar (escola pública ou privada) e a escolaridade de seus pais e cor do estudante.

Bastariam alguns exemplos expostos por esse autor para constatar: 1) que a realidade socioeconômica e a desigualdade social condicionam o acesso à ES; 2) que medidas e açóes do Estado podem ser eficazes no combate de algumas das decorrências dessa desigualdade e favorecer, até certo ponto, a produção de condiçôes de igualdade de acesso a esse nível da educação, isto é, a sua, ainda que precária, democratização.

Se tomada a variável renda familiar como referência e forem cruzados os percentuais de estudantes oriundos de famílias de renda superior a 10 SM (7\% na sociedade) dos três ciclos do Enade (2006, 2009 e 2012) com quatro cursos selecionados, ter-se-á: 1) no Curso de Medicina, os estudantes oriundos dessas famílias com renda superior a 10 SM eram 67\%, no $1^{\circ}$ ciclo, $70 \%$ no 2o e $44 \%$ no $\left.3^{\circ} ; 2\right)$ no Curso de Odontologia, eram $56 \%$ no $1^{\circ}$ ciclo, $50 \%$ no $2^{\circ}$ e $28 \%$ no 3 ; 3 ) no Curso de Direito, eram $37 \%$ no $1^{\circ}$ ciclo, $26 \%$ no $2^{\circ}$ e $24 \%$ no 3o; 4 ) no Curso de Psicologia, eram $32 \%$ no $1^{\circ}$ ciclo, $19 \%$ no $2^{\circ}$ e $16 \%$ no $3^{\circ}$.

Por outro lado, esses estudos mostram que se fortalece a tendência de os estudantes oriundos de famílias de renda de até 3 SM buscarem preferencialmente os cursos de baixa demanda ("pobres”), como História e Pedagogia, e não os cursos de alta demanda ("nobres"), como Medicina e Odontologia.

Observa-se, entre outros, que Medicina e Odontologia, que têm a menor representação na faixa de até 3 salários mínimos, têm expressiva representação nas duas faixas superior, de 10 a 30 e mais de 30 salários mínimos. Note-se igualmente que 14\% dos estudantes de Medicina vêm de famílias com faixa de renda de mais de 30 salários mínimos mensais, enquanto História e Pedagogia têm representação próxima de zero nesta mesma faixa de renda. (RISTOFF, 2014, p. 737)

Se tomada a variável origem escolar - escola privada ou pública - verifica-se um fenômeno algo semelhante ao anterior: enquanto $87 \%$ dos alunos do ensino médio frequentam escolas públicas, no final do $1^{\circ}$ ciclo do Enade (2006) apenas $46 \%$ dos estudantes da educação superior provinham de escolas públicas; no final do $2^{\circ}$ ciclo (2009) este percentual subiu para 51\%; e, no final do $3^{\circ}$ ciclo (2012), já havia atingido 60\%. Entretanto, as discrepâncias verificadas no caso da renda familiar quando confrontada com cursos "nobres" e "pobres" tendem a repetir-se: ao final do $3^{\circ}$ ciclo do Enade (2012), do total de estudantes de Medicina, apenas $11 \%$ haviam cursado o ensino médio público; de Odontologia, 25\%; de Direito, 43\%; de Psicologia, 49\%; de História, 70\%; de Pedagogia 81\%. 
A evolução percentual de oriundos do ensino médio público do $1^{\circ}$ para os $2^{\circ}$ e $3^{\circ}$ ciclos do Enade nos diferentes cursos deu-se de forma mais lenta que no caso da renda familiar: no Curso de Medicina, foi de $9 \%$ no $1^{\circ}$ ciclo a $11 \%$ no $2^{\circ}$ e no $3^{\circ}$; no de Odontologia, foi de $17 \%$ no $1^{\circ}$ para $24 \%$ no $2^{\circ}$ e $25 \%$ no $3^{\circ}$; no de Direito, foi de $40 \%$ no $1^{\circ}$ para $42 \%$ no $2^{\circ}$ e $43 \%$ no $3^{\circ}$; no de História, foi de $63 \%$ no $1^{\circ}$ para $67 \%$ no $2^{\circ}$ e $70 \%$ no $3^{\circ}$; no de Pedagogia, foi de $71 \%$ no $1^{\circ}$ para $77 \%$ no $2^{\circ}$ e $81 \%$ no $3^{\circ}$.

Por fim, eis algumas constataçóes do autor desses dois estudos a respeito da mudança de perfil dos estudantes da educação superior a partir dos três ciclos do Enade, e ao longo da vigência dos programas Prouni, Fies e Lei das Cotas, entre outros:

Os dados do Questionário Socioeconômico dos dois (sic) primeiros ciclos completos do Enade revelam que houve, de 2004 a 2012, em todos os cursos, uma diminuição percentual de estudantes oriundos de famílias de alta renda (mais de 10 salários mínimos). Mesmo assim, é possível inferir que persiste uma expressiva distorção de natureza socioeconômica no campus brasileiro. [...]

A origem social e a situação econômica da família do estudante é, sem dúvida, um fator determinante na trajetória do jovem brasileiro pela educação superior e, por isso mesmo, deve estar na base das políticas públicas de inclusão dos grupos historicamente excluídos. (RISTOFF, 2014, p. 742-43)

Com relação à origem escolar dos estudantes, além de constatar que nenhum curso atinge a paridade de $87 \%$ de alunos do ensino médio público e que apenas 7 de 47 cursos sob análise têm mais de $70 \%$ de oriundos de escolas públicas, o autor observa:

Percebe-se, portanto, uma enorme distância entre os percentuais dos diferentes cursos, deixando evidente que os maiores percentuais de estudantes oriundos da escola pública tendem a estar em cursos de demanda mais baixa, enquanto, nos de demanda mais alta, os estudantes da escola pública estáo significativamente sub-representados. (RISTOFF, 2014, p. 745)

Embora o autor veja com certo otimismo a confirmação das mudanças do perfil socioeconômico dos estudantes de graduação a partir dos dados fornecidos pelos três ciclos do Enade, é possível levantar algumas questóes quanto aos limites desses avanços. 
Essa mudança de perfil não poderá se sustentar nem diminuir suas distorções se não forem fortalecidas as políticas sociais de caráter universal que garantam a redução efetiva das desigualdades sociais. Além do que, outros fatores como a dependência das IES particulares, com fins lucrativos, em relação a programas como Prouni e especialmente o Fies, em tempos de crise da economia, de avanço do déficit público, poderá estancar ou diminuir significativamente tais avanços.

Quanto à desigualdade social, ainda que programas como o Bolsa Família e o aumento real do salário mínimo tenham reduzido os índices de pobreza, segundo o economista Paulo Passarinho, essa melhora seria apenas marginal: o Brasil teria melhorado muito pouco sua posição na lista dos países mais desiguais. (PASSARINHO, 2011)

Sérgio Leite (2013), examinando dados de pesquisa recente, alerta:

Segundo pesquisa do Datafolha [Folha de S. Paulo, 22 de janeiro de 2012], 28\% dos brasileiros são caracterizados como excluídos, ou seja, pertencentes à faixa socioeconômica mais baixa. Considerando-se ainda que $18 \%$ situam-se na classe média-baixa, imediatamente superior à anterior, pode-se afirmar que quase metade da população - $46 \%$ - sofre, em alguma dimensão, o processo de exclusão. Por exemplo, essas duas faixas da populaçáo estáo, praticamente, ausentes dos índices de conclusão dos ensinos médio e superior. (LEITE, 2013, p. 19)

Ainda que a desigualdade tenha diminuído nos anos recentes, o índice Gini $^{14}$ continua muito alto, tendo, de 2009 a 2011, por exemplo, apenas baixado de 0,518 para 0,501 , e isto em razão do aumento do salário mínimo, embora, como diz Abdala (2012), o pessoal de menor renda nem receba o salário mínimo. ${ }^{15}$

Tão importante quanto a desigualdade social é a questão da escolha de cursos e instituiçóes pelos jovens que se beneficiariam do Prouni e do Fies. Tanto as bolsas (integrais, parciais de $50 \%$ ou 25\%) do Prouni, como os empréstimos do Fies são exclusivamente destinados a estudantes das IES privadas, $90 \%$ das quais são particulares ou privado-mercantis. Em 2013, quase 1/3 (31\%) das 5.345 mil matrículas em IES privadas eram beneficiárias do Prouni $(9,6 \%)$ e do Fies $(21,4 \%)$.

\section{II.2 - 0 impacto das novas regras do Fies e alguns traços característicos das IES dependentes desse Fundo}

As Portarias 21 e 23 do Fies, de 29 de dezembro de 2014, que endureceram os critérios para concessão dos empréstimos desse Fundo, causaram enorme 
impacto sobre o conjunto das IES beneficiárias. Segundo analistas (HOPER, $12 / 02 / 2015$ ), essa mudança de critérios (nota superior a 450 no Enem, nota superior a zero na redação e cronograma de desembolso dos recursos do Fundo em oito parcelas em lugar de 12) significaria uma redução de um terço dos beneficiários ou redução de $8 \%$ a $35 \%$ do total de matrículas, a depender do grau de adesão de cada IES a esse Programa. ${ }^{16}$

Em consequência disso, as quatro companhias, lideradas pela Kroton/ Anhanguera, mais lucrativo dos 15 setores da Bovespa nos últimos dois anos até dezembro de 2014, perderam nos quatro primeiros meses de 2015 entre $30 \%$ e $50 \%$ do valor de suas açóes. De acordo com Umpieres (2015), o Fies responde por 49\% das receitas totais da Ser Educacional (SEER3), 44\% da Kroton (KROT3), 40\% da Estácio (ESTC3) e 38\% da Anima (ANIM3). (UMPIERES, 2015).

\section{II.3 - Permanência e sucesso na educação superior}

No estudo diagnóstico sobre a Política de expansão da ES (SGUISSARDI, 2014, p. 81), referência básica destas reflexões, a propósito da permanência e sucesso na ES, lê-se:

A expansão da ES, para ser democrática e não se tornar mera massificação, deve apoiar-se em pelo menos dois componentes: igualdade de condiçôes de acesso, de escolha de cursos e carreiras a cursar, e de permanência com sucesso até a titulação.

Para dar consistência a essa afirmação a respeito desses dois fatores de democratização ou massificação são importantes as conclusôes de estudo de Almeida et al. (2014, p. 907) que mostram que a democratização da ES também deveria levar em conta "[...] frequência, sucesso acadêmicos e conclusão dos cursos por parte dos alunos [...] ". É na análise desta realidade que os autores, apoiados em estudos de uma dezena de especialistas, alertam para o fenômeno denominado de "exclusão dos incluídos":

[...] o "aluno novo" consegue ter acesso ao ensino superior, mas tem inúmeras dificuldades para manter-se nesse segmento respondendo às expectativas de sucesso acadêmicos. Torna-se, simbolicamente, "excluído" após ter sido "incluído". Na esteira desses argumentos, pesquisas questionam, inclusive, a democratizaçáo no acesso visto que a escolha pelo curso, carreira ou profissão não é prerrogativa do estudante, sendo-lhe antes "circunstancializada" pelo seu perfil (ZAGO, 2006). Há, a despeito da massificação do ensino superior - ou em razáo dela -, uma desigualdade de oportunidades ao acesso, construída histórica e 
socialmente: "Para a grande maioria não existe verdadeiramente uma escolha, mas uma adaptação, um ajuste às condições que o candidato julga condizentes com sua realidade e que representam menor risco de exclusão" (p. 9). (ALMEIDA, 2014, p. 906-7, apud SGUISSARDI, 2014, p. 81)

$\mathrm{Na}$ conclusão deste estudo, as questōes que levantam ajudam a entender a disjuntiva aqui proposta como subtítulo desta exposição:

Assim, é no mínimo questionável se a expansão ocorrida no ensino superior se traduziu numa efetiva democratização do acesso, mais ainda quando se pretende estender essa democratização ao sucesso acadêmico dos estudantes. (ALMEIDA, 2014, p. 907, apud SGUISSARDI, 2012, p. 81)

Acrescente-se, no caso brasileiro, o fato de essa expansão apoiar-se essencialmente na ES particular e com fins de lucro, como demonstrado.

\section{II.4 - Alguns dados}

Para responder à questão - democratização ou massificação mercantil? alguns dados estatísticos dos últimos 10 a 15 anos são esclarecedores.

1. O total de IES de 1999 a 2010 passa de 1.097 para 2.378 , com $116 \%$ de crescimento. Mas as IES públicas aumentam em número apenas $44,8 \%$, isto é, de 192 para 278, enquanto as IES privadas têm aumento de $132 \%$, isto é, passam de 905 a 2.100 , e, dentre estas, as IES comunitárias ou confessionais têm uma redução de $34 \%$, ou seja, passam de 379 para 250, enquanto as IES particulares ou com fins de lucro têm um aumento de $252 \%$, mais do que dobro do total das IES do país (116\%), isto é, passam de 526 para 1.850. As proporçóes que eram, em 1999 - 17,5\% públicas; 34,5\% comunitárias ou confessionais; e $48 \%$ particulares ou com fins de lucro - passam, em 2010, para: 11,7\% públicas; $10,5 \%$ comunitárias ou confessionais; e $77,8 \%$ particulares ou com fins de lucro.

2. O total de matrículas de 1999 a 2010 passa de 2.369 mil para 5.449 mil, com $130 \%$ de crescimento. Mas as IES públicas aumentam seu total em apenas $75,7 \%$, isto é, de 832 mil para 1.461 mil, enquanto as IES privadas têm aumento de 159\%, isto é, passam de $1.537 \mathrm{mil}$ para 3.987 mil, e dentre estas, as IES comunitárias ou confessionais têm uma redução de 32\%, ou seja, passam de 886 mil para $600 \mathrm{mil}$, 
enquanto as IES particulares ou com fins de lucro têm um aumento de $420 \%$, mais de três vezes do total das matrículas do país (130\%), isto é, passam de 651 mil para 3.387 mil. As proporçóes que eram, em 1999 $35 \%$ públicas; $37 \%$ comunitárias ou confessionais; e $27 \%$ particulares ou com fins de lucro - passam, em 2010, para: 27\% públicas; $11 \%$ comunitárias ou confessionais; e $62 \%$ particulares ou com fins de lucro.

3. O total de matrículas das três companhias remanescentes das que abriram o capital e fizeram o IPO em 2007 era, em 2008, de 367 mil ou 9,5\% do total de estudantes do setor privado que somava 3.858 mil; passados cinco anos, em 2013, esse total havia chegado a 1.276 mil ou $23 \%$ do total de matrículas das IES privadas que era de 5.448 mil. A empresa que mais cresceu nestes cinco anos foi a Kroton (Pitágoras) que passou de 26 mil matrículas ou $0,7 \%$ do mercado para 519 mil ou $9,5 \%$ do mercado. A incorporação da Anhanguera Educacional pela Kroton, em julho de 2014, constituiu a maior companhia no mercado educacional do mundo, com um total de cerca de um milhão de matrículas na ES, distribuídos por 130 IES, sendo apenas duas universidades, e 500 mil alunos de educação básica, distribuídos por 876 escolas associadas. A Kroton conta com 37 mil funcionários (dados de junho de 2014). A alta direção dessa empresa é composta de três diretorias e nove vice-presidências. Dentre essas, uma "Diretoria de Relações com Investidores" e uma "Vice-presidência de Marketing e Vendas".

4. Distribuição e evolução das matrículas presenciais de graduação por turno (diurno e noturno) e categoria administrativa de 2002 a 2012. Para um aumento de $70 \%$ no montante de matrículas, o turno diurno teve um aumento de $48 \%$ e o noturno, de $86,6 \%$. A proporção dos turnos em 2002 era: 42\% diurno e 58\% noturno; em 2012: 37\% diurno e $63 \%$ noturno. Das matrículas das IES públicas, $63 \%$ estudam no turno diurno e $37 \%$ no turno noturno; das matrículas das IES privadas, $73,2 \%$ estudam no turno noturno e $26,8 \%$ no turno diurno.

5. Distribuição e evolução das matrículas de $\mathrm{EaD}$ por categoria administrativa de 2002 a 2012. Para um aumento de $1.768 \%$ (40 mil para 1.113 mil) das matrículas de $\mathrm{EaD}$ no período, as públicas aumentaram $404 \%$ e as privadas, $2.946 \%$. Em 2002, a proporção era de $84 \%$ de matrículas públicas e 16\% privadas; em 2012, 16\% eram matrículas públicas e $84 \%$ privadas. Do total de matrículas de 2009, 89\% concentravam-se nas áreas de educação (pedagogia e licenciaturas) e Negócios, Direito e Ciências Sociais.

6. Distribuição dos docentes em exercício na ES de graduação por grau de formação de 2003 a 2012. Em 2003, os docentes com graduação e 
especialização eram 48\% do total nas IES privadas e 29,5\% nas IES públicas; em 2012, eram 36,8\% nas IES privadas e 18\% nas IES públicas. Em 2003, os docentes com mestrado eram 39\% nas IES privadas e 27\% nas IES públicas; em 2012, eram 45,7\% nas IES privadas e 29\% nas IES públicas. Em 2003, os docentes com doutorado eram 11,5\% nas IES privadas e 39,7\% nas IES públicas; em 2012, eram 17,9\% nas IES privadas e $51 \%$ nas IES públicas.

7. Distribuição dos docentes em exercício por regime de trabalho segundo as categorias administrativas pública federal e privada em 2012. O regime de trabalho dos docentes das IES federais assim se distribui: $1 \%$ horistas; $8 \%$ tempo parcial; e $91 \%$ tempo integral. O regime de trabalho dos docentes das IES privadas: 41\% horistas; 34\% tempo parcial; e $24 \%$ tempo integral.

8. A relação professor/alunos nas 108 universidades públicas, em 2012, é $1 / 13$; a das 85 universidades privadas é de $1 / 33$. A relação tempo integral/matrículas é de 1/16 nas universidades públicas e 1/88 nas universidades privadas.

9. Em 2012, das oito grandes áreas de conhecimento - Educação; Humanidades e Artes; Ciências Sociais, Negócios e Direito; Ciências, Matemática e Computação; Engenharia, Produção e Construção; Agricultura e Veterinária; Saúde e Bem Estar Social; e Serviços - as IES públicas destacam-se por concentrarem mais matrículas do que sua proporção no total de matrículas (27\%) nas áreas de Agricultura e Veterinária (62\%), Educação (54\%), Ciências, Matemáticas e Computação $(40,3 \%)$ e Humanidades e Artes (31,8\%); as IES privadas, por concentrarem suas matrículas mais do que sua proporção no total de matrículas $(73 \%)$ nas áreas de Ciências Sociais, Negócios e Direito $(84,3 \%)$, Saúde e Bem-Estar Social (76,8\%) e Serviços (76,6\%). As IES privadas concentram $48 \%$ de todas as suas matrículas em Ciências Sociais, Negócios e Direito, restando 52\% para as demais sete grandes áreas do conhecimento.

\section{Considerações finais}

Diante do exposto pode-se afirmar que se sustenta a pergunta inicial que põe em questão o caráter democrático da política de expansão da ES das últimas décadas no Brasil? Confirmar-se-ia a hipótese de que a massificação mercantil se sobreporia à democratização dessa expansão? Ou a hipótese de que a política de expansão da ES no Brasil, especialmente através de programas como o Prouni e 
o Fies, é uma política pública de caráter focal e compensatória das desigualdades sociais produzidas pelo modelo de desenvolvimento em curso? Caber-lhe-ia o qualificativo de uma política de massificação mercantil? Ou a afirmação de estar pondo em prática uma concepção de ES que confunde educação superior, como direito ou "serviço público", com "serviço comercial" ou mercadoria? De não ser uma política social autônoma mas a cada dia mais dependente dos interesses do mercado? De continuar a implementar a expansão de uma educação de elite e de alta "qualidade" para poucos e uma educação de massa e de baixa "qualidade" para muitos?

Certamente os dados e as observaçóes visando interpretá-los postos até aqui não permitem respostas conclusivas a nenhuma das questóes acima reiteradas, mas permitem pôr em questão, do ponto de vista da democratização que pressupóe o máximo de igualdade de condiçóes, a atual política de expansão da ES no Brasil. Permitem que - com base na distribuição e evolução do número de instituiçóes e matrículas públicas e privadas, especialmente particulares ou privado-mercantis; na concentração por área de conhecimento, por turnos de estudo; nas condições de acesso e permanência; na maior ou menor "exclusão dos incluídos"; e no processo de mercadização/mercantilização etc. - se possa levantar tais questóes de forma bastante consistente.

Como escrito no estudo diagnóstico sobre a política de expansão que serviu de principal referência para este texto,

[...] respostas mais precisas e consistentes devem ser fruto do debate democrático em todas as instâncias do Estado e da sociedade civil em que a expansáo democrática da educação superior puder ser objeto de interesse e um desafio a ser necessariamente superado. (SGUISSARDI, 2014, p. 177/78)

E quanto ao que não se pode pôr em dúvida - “[...] que o campus [ES] é um espelho que distorce a imagem da sociedade [... e que] como um agente social ativo, aguça as distorçóes existentes na sociedade [...]" (RISTOFF, 2014, p. 731) - o que se impóe a todos nós é, antes de tudo, a luta por políticas de caráter universal que combatam a desigualdade social vigente, sem abrir mão das políticas focais que garantam avanços na democratização do acesso à ES e da permanência nela até o final dos estudos, a partir da definição de prioridades, com base em adequado diagnóstico da área, como parte de um Plano Nacional de Graduação ou algo equivalente. 


\section{Notas}

1. Conferência de encerramento, proferida no dia 17/06/2015, no V Seminário de Educação Brasileira - Mudanças Atuais na Sociedade Brasileira e o Sistema Nacional de Educação: qualidade da educação pública como Direito Humano, promovido pelo Centro de Estudos Educaçáo e Sociedade (Cedes). Campinas, de 15 a 17/06/2015.

2. Em meio à crise na qual vive o país, em especial o setor industrial, com o desemprego saltando em poucos meses de cerca de $5 \%$ para $7 \%$ ou $8 \%$ da população economicamente ativa, os bancos do Brasil, Bradesco e Itaú apresentaram no primeiro trimestre de 2015 um superávit acumulado, desses três, superior a 15 bilhôes de reais $(\mathrm{R} \$ 15.790 \mathrm{mi})$ que corresponde a cerca de $2 / 3$ do total anual gasto com o Programa Bolsa Família em 2014 que beneficiaria cerca de 80 milhóes de cidadãos. (Ver: Lucro do Banco do Brasil cresce 117,3\% no trimestre, para R \$ 5,81 bilhóes, Folha de S. Paulo, quinta-feira, 4 de junho de 2015).

3. Private equity é um tipo de atividade financeira realizada por instituiçóes que investem essencialmente em empresas que ainda não são listadas em bolsa de valores, com o objetivo de alavancar seu desenvolvimento. Esses investimentos são realizados via Fundos de Private Equity.

4. IPO (do inglês Initial Public Offering ou Oferta Pública Inicial) é o processo pelo qual as açôes de uma empresa são vendidas ao público (pessoas físicas e pessoas jurídicas) pela primeira vez, via Bolsa de Valores (no caso Bovespa). É o processo pelo qual uma empresa torna-se uma empresa ou sociedade anônima de capital aberto.

5. "A GP Investments é uma companhia líder em investimentos alternativos na América Latina, com forte atuação em gestão de recursos, principalmente em fundos de private equity. [...] soma mais de 50 empresas investidas e US\$5 bilhóes captados de investidores de todas as partes do mundo". Disponível em: <http://www.gp.com.br/gp2012/web/conteudo pt.asp?idioma=0\&conta=28\&ti po $=42978>$. Acesso em 03/08/2014. O Fundo GP vendeu sua participação na Estácio, que era de 7,5\% de seu capital social, em setembro de 2013, por US\$179,1 milhôes. Disponível em: < $\underline{\text { http:// }}$ veja.abril.com.br/noticia/economia/gp-investments-vende-sua-participacao-na-estacio $>$. Acesso em 03/08/2014.

6. O Pátria é um dos maiores fundos de investimentos atuando no país, em parceria com o fundo de investimentos internacional Blackstone. Disponível em: <http://www.blackstone.com/the-firm/ overview /history>. Acesso em 03/08/2014. Desde a década de 1990 participa do setor de private equity no Brasil. "Ao longo do tempo, em resposta às necessidades de nossos investidores e clientes e às oportunidades apresentadas pelo dinâmico crescimento econômico do país, o Pátria expandiu gradualmente seu portfólio com a criação de novos negócios nas áreas de assessoria financeira, capital management, infraestrutura e real estate". Disponível em: <http://www.patriainvestimentos.com.br/ pt/TheFirm $>$. Acesso em 03/08/2014.

7. O fundo Advent International investe em mais de 280 companhias em 36 países, tendo dado suporte a $140 \mathrm{IPOs}$ (lançamento de açóes) em bolsa de valores do mundo todo. Disponível em:

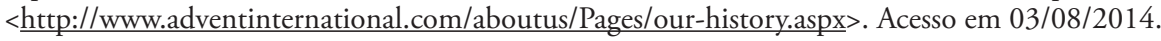

8. Kohlberg Kravis Roberts \& Co. L. P. (KKR) é um dos maiores fundos internacionais de investimento em private equity, infraestrutura, real estate e outros, atuando em dezenas de países do mundo. Disponível em: <http://www.kkr.com/businesses/private-markets>. Acesso em 03/08/2014.

9. O Grupo Cartesian Capital (antes de 2006, AIG Capital Partners, Inc ou AIGCP) atua nos mercados emergentes de private equity, administrando mais de US\$ 5 bilhóes de dólares. Em 10 anos administrou mais de 50 investimentos em 24 países. Disponível em: <http://cartesiangroup.com/ history.html>. Acesso em 03/08/2014.

10. O Capital Group é um dos mais antigos fundos de investimento americanos (1931). Segundo sua home page na internet, administraria um patrimônio superior a US\$ 1,25 trilhão ao redor do mundo. Disponível em: <https://www.thecapitalgroup.com/our-services.html $>$. Acesso em 
03/08/2014.

11. A Fama Investimentos, fundada em 1993, no Brasil, tendo hoje, segundo informa, mais de US\$ 600 milhōes de ativos sob sua gestão, "[...] sendo a maioria fruto de investimentos de estrangeiros, como fundos de pensão, endowments e seguradoras [...]".

12. O Best Associates é um banco comercial, com sede em Dallas, Texas, USA, que atua nos Estados Unidos e em outros países, como o Brasil. Cumpre funçôes de um fundo de investimento. Disponível em: <http://www.bestassociates.com/profile.html>. Acesso em 03/08/2014.

13. Esse Decreto foi revogado pelo de n. 3.860/01 e, este, pelo Decreto, chamado Ponte, n. 5.773/06. Ambos, porém, neste particular, mantêm a distinção e o reconhecimento das IES sem e com fins lucrativos.

14. O índice Gini varia de 0 a 1; quanto mais próximo de 1, maior a desigualdade.

15. Sobre a distinção entre diminuição da pobreza absoluta e extrema, e desigualdade de renda, ver Bocchini, 2010.

16. Segundo matéria intitulada "7 gráficos que explicam a farra do financiamento estudantil", de Paulo Saldaña e Rodrigo Burgarelli, no Estado de S. Paulo, de 04 de março de 2015, havia Faculdade com $90 \%$ dos seus alunos beneficiários do Fies.

\section{Referências}

ABDALA, V. Rendimento do trabalhador brasileiro cresce e distância entre pobres e ricos diminui. Agência Brasil. 21/09/2012. Disponível em: <http://agenciabrasil.ebc.com. br/noticia/2012-09-21/rendimento-do-trabalhador-brasileiro-cresce-e-distancia-entre-pobres-e-ricos-diminui>. Acesso em 18/07/2013

ALMEIDA, L. et al. Democratização do acesso e do sucesso no ensino superior: uma reflexão a partir das realidades de Portugal e do Brasil. Avaliação, Campinas, v.17, n. 3, nov. 2012. Disponível em: <http://dx.doi.org/10.1590/S1414-40772012000300014 >. Acesso em 24/07/2014.

BELLONI, I; MAGAlHÂES, H. de; SOUSA, L. C. de. Metodologia de Avaliação em Políticas Públicas. São Paulo: Cortez - Questôes de Nossa Época, 2000.

BOCCHINI, B. Pobreza no Brasil cai mais rápido do que desigualdade de renda. Fundação Lauro Campos. Disponível em: <http://laurocampos.org.br/2010/01/pobreza-no-brasiul-cai-mais-rapido-do-que-desigualdade-de-renda/>. Acesso em 10/07/2014.

BRAGA, R. Setor financeiro avança no comando de unidades de educação privada. Hoper. Disponível em: <http://www.hoper.com.br/artigo-hoper.php?id=24 $>$. Acesso em $02 / 08 / 2014$.

BRASIL. Constituição (1988). Constituição da República Federativa do Brasil. Brasília, DF: Senado Federal, 1988.

BRASIL. Lei no 9.394/96, de 20 de dezembro 1996. Estabelece as diretrizes e bases da educação nacional. Brasília, DF., Diário Oficial da Uniáo, 23 dez. 1996. 
BRASIL. Decreto n. 2.207, de 15 de abril de 1997. Regulamenta, para o Sistema Federal de Ensino, as disposiçóes contidas nos arts. 19, 20, 45, 46 e $\$ 1^{\circ}$, 52, parágrafo único, 54 e 88 da Lei n. 9394, de 20 de dezembro de 1996, e dá outras providências. Brasília, DF., Diário Oficial da Uniáo - Seção 1 - 16/4/1997, Página 7534 (Publicação Original).

. Decreto no 2.306, de 19 de agosto de 1997. Regulamenta, para o Sistema Federal de Ensino, as disposiçôes contidas no art. 10 da Medida Provisória no 1.477-39, de 8 de agosto de 1997, e nos arts. $16,19,20,45,46$ e $\$ 1^{\circ}, 52$, parágrafo único, 54 e 88 da Lei no 9.394, de 20 de dezembro de 1996, e dá outras providências. Brasília, DF., Diário Oficial da Uniáo - Seção 1 - 20/8/1997, Página 17991 (Publicação Original).

FREIRE, V. T. Revisão mostra o país um pouco mais pobre. Folha de S. Paulo, sábado, 20 set. 2014. Disponível em: <http://www1.folha.uol.com.br/fsp/mercado/186574-revisao-mostra-pais-um-pouco-mais-pobre.shtml $>$. Acesso em 20/09/2014.

HOPER CONSULTORIA. O impacto das mudanças do Fies na educação superior brasileira. 12/02/2015. Disponível em: <http://www.hoper.com.br/\#!O-IMPACTO-DAS-MUDAN\%C3\%87AS-DO-FIES-NA-EDUCA\%C3\%87\%C3\%83O-SUPERIOR-BRASILEIRA/cupd/2FDF66AA-7828-4417-9C16-6B4B1F060446>. Acesso em 05/05/2015.

IANNI, O. Estado e capitalismo. 2a ed., São Paulo: Brasiliense, 2004.

LEITE, S. A. da S. Afetividade e letramento na EJA. In: - Afetividade e letramento na educação de jovens e adultos - EJA. São Paulo: Cortez, 2013, p. 19-62.

MAIA, S. Mercado nota 10 - Com empurrão público, as faculdades privadas atraem investidores. Carta Capital, Ano XX, n. 799, 14/05/2014.

NETTO, J. P.; BRAZ, M. Economia Política - uma introdução crítica. São Paulo: Cortez, 2007.

PASSARINHO, P. A desigualdade brasileira. Fundação Lauro Campos, 3 de novembro de 2011. Disponível em: <http://laurocampos.org.br/2011/11/a-desigualdade-brasileira/>. Acesso em 10/07/2014.

RISTOFF, D. Perfil socioeconômico do estudante de graduação. Uma análise de dois ciclos completos do Enade (2004 a 2009). Cadernos GEA, Brasília, n. 4, jul./dez. 2013.

. O novo perfil do campus brasileiro: uma análise do perfil socioeconômico do estudante de graduação. Avaliação, Campinas; Sorocaba, SP, v. 19, n. 3, p. 723-747, nov. 2014 .

SGUISSARDI, V. Estudo Diagnóstico da Política de Expansão da (e Acesso à) Educação Superior no Brasil-2002-2012. Brasília: Edital N. 051/2014 SESU; Projeto de Organismo Internacional - OEI; Projeto OEI/BRA/10/002, 2014.

UMPIERES, R. T. Entenda por que o melhor setor da Bolsa em 2014 já caiu mais de 40\% em 2015. INFOMONEY.COM.BR, 13 jan. 2015. Disponível em: <http://www. infomoney.com.br/mercados/acoes-e-indices/noticia/3803845/entenda-por-que-melhor-setor-bolsa-2014-caiu-mais-2015>. Acesso em 05/05/2015. 
VALE, A. A. do; CHAVES, V. L. J.; CARVALHO, C.H. de A. Estratégias de expansão do segmento privado-mercantil do ensino superior brasileiro e suas repercussóes no trabalho docente. In: CONGRESSO BRASILEIRO DE SOCIOLOGIA, 16., 2013. Salvador, BA. Anais ... Salvador: SBS, 2013.

WORLD BANK. Financing education in developing countries - An exploration of policy options. Washington, DC: The World Bank, 1986.

. Higher education: the lessons of experience. Washington, DC: The World Bank Group, 1994. (Series Development in Practice).

. The financing and management of higher education - A status report on worldwide reforms. Elaborado por D. Bruce Johnstone, com colaboração de Alka Arora e William Experton. Washington, DC: The World Bank, 1998.

. Task Force on Higher Education and Society. Higher education in developing countries: peril and promise. Washington, DC: The World Bank, 2000. Disponível em: <http://www.tfhe.net>. Acesso em: 20 jul. 2004.

XAVIER, M. E. S. P.; DEITOS, R. A. Estado e política educacional no Brasil. In: DEITOS, Roberto A.; RODRIGUES, Rosa M. (Org.). Estado, desenvolvimento, democracia \& politicas sociais. Cascavel, PR: EDUNIOESTE, 2006, p. 67-86.

Recebido em 20 de outubro de 2015.

Aprovado em 23 de outubro de 2015.

DOI: http://dx.doi.org/10.1590/ES0101-73302015155688 